\title{
Formación Permanente del Profesorado para la Inclusión Educativa, Mediada por Narraciones Fotográficas
}

\section{Permanent Teacher Training for Educational Inclusion, Mediated by Photographic Narratives}

\author{
Antonio Bautista* \\ Laura Rayón \\ Universidad Complutense de Madrid, España
}

\begin{abstract}
En este artículo se fundamenta la naturaleza inclusiva de la narración fotográfica en situaciones de enseñanza mediada por híbridos digitales. Responde a la preocupación por la proliferación de expresiones sobre el uso de medios tecnológicos en ambientes de formación que no ayudan a entender lo que se está haciendo, ni a plantear acciones con estas herramientas para promover procesos mentales superiores $y$, consecuentemente, el desarrollo del alumnado y profesorado en ambientes educativos diversos e inclusivos. Se plantea cuál es la esencia de los procesos de inclusión educativa para, posteriormente, analizar qué saberes y principios de procedimiento debe tener el profesorado para atender y mantener el valor de este tipo de educación. Con ese fin, se revisan los diferentes enfoques aportados por la teorización sobre el currículum. Se concluye afirmando que, desde un punto de vista de la educación inclusiva, se han de promover relaciones interpersonales del alumnado en su grupo de referencia. El resultado del proceso de construcción de significados de forma compartida, así como de las conclusiones del análisis, cuestionamiento y deliberaciones emergentes al contrastar diferentes miradas sobre el contenido de las imágenes tomadas por el grupo conjuntamente, favorecerá el conocimiento mutuo de los participantes en dichas situaciones formativas.
\end{abstract}

Descriptores: Desarrollo profesional docente; Formación permanente; Educación inclusiva; Narración; Fotografía.

This article corroborates the inclusive nature of photographic narrative in teaching situations mediated by digital hybrids. It represents an attempt to address growing concern about use of technological media in teaching that does not facilitate the learning process or leverage these tools by proposing actions that promote higher mental processes and consequently the development of students and teachers in diverse and inclusive educational environments. The essence of inclusive education processes is discussed, followed by an analysis of the knowledge and procedural principles that teachers should possess in order to attend to and maintain the value of this type of education. To this end, a review is conducted of the different approaches to curriculum theory. The article concludes by stating that from the perspective of an inclusive education, it is necessary to promote students' interpersonal relationships within their peer group. The process of jointly constructing meanings and drawing conclusions from the analysis, questioning and deliberations that emerge when contrasting different views on the content of images taken by the group facilitates participants' mutual knowledge in these training situations.

Keywords: Teacher professional development; Lifelong learning; Inclusive education; Narration; Photography. 


\section{Introducción}

La temática del título de este artículo está motivada por dos preocupaciones; una, es la insuficiente presencia de unos contenidos en la formación inicial del profesorado que le lleve a conocer la esencia, y consecuente exigencia, de una educación inclusiva frente a la denominada integradora. La otra, atiende a la baja frecuencia de situaciones de narración fotográfica en la trayectoria profesional de los docentes que, inscrita en su formación permanente, de respuesta a la preocupación anterior.

Debemos señalar que la naturaleza de ambas inquietudes reside en la herencia del lenguaje y de la práctica educativa que recibimos en ámbitos de formación docente. Puede decirse que somos víctimas de dicha herencia porque si nos detenemos a analizar este lenguaje, aparentemente sencillo en entornos educativos, gran parte del mismo nos llevará a preguntarnos e indagar en el significado de buena parte de lo que escuchamos. A modo de ejemplo, con frecuencia se habla de atención a la diversidad, pero no se especifica si la naturaleza de la misma es físico-cognitiva o, además de esta, también es sociocultural. De igual forma, se habla de diferencias en el alumnado, pero no sobre su sentido; es decir, no se cuestiona porqué si es algo extraordinario hay que abordarlo con adaptaciones individuales instructivas, y no incorporarlo como algo valioso que enriquece situaciones formativas de conocimiento mutuo.

En este sentido, a veces se oyen recomendaciones de aplicar los actuales híbridos digitales (Smartphones, tabletas, ordenadores portátiles, etcétera) en la enseñanza por los beneficios que aportan, pero son expresiones que no ayudan a entender la distinción entre emplear, utilizar y usar tales productos digitales, ni la función del alumnado y profesorado en estas aplicaciones, ni la formación que hay que proporcionarles para que las bondades anunciadas se materialicen en los procesos de enseñanza y de aprendizaje (Bautista, 2021).

En fin, si no se hace esta explicitación del significado de las palabras no se podrá especificar ni matizar que un programa de integración de alumnado diverso se limita a su incorporación espacial en un centro o institución educativa, porque uno de inclusión busca una incorporación afectiva y social de todo el alumnado además de la de convivir en un mismo lugar.

Esta preocupación está asociada a que normalmente el profesorado no cuestiona la falta de sentido de esas prácticas y la terminología del lenguaje, ni el modelo curricular que las sustenta, no lo hace a pesar de que no le reporta comprensión de lo que ocurre en aulas y centros, a pesar de que no le ayuda a concretar un plan de acción ante situaciones emergentes de enseñanza, que son únicas e irrepetibles. No lo hace por temor a ser considerado como ignorante o, en el peor de casos, estúpido. Tiene que llegar alguien ajeno al aula y centro que, con su ingenuidad, pregunte sobre todo lo que se hace y dice, pero no entiende, tiene que llegar un niño, como en el cuento El nuevo traje del Emperador de Hans Christian Andersen, para decir que el Emperador está desnudo.

Consideramos que la ingenuidad que desvela la verdad de cierta terminología está asociada a nuevos procedimientos y formas de observación que, ineludiblemente, lleven a poner el foco en nuevos aspectos de las situaciones vividas en centros educativos. Es así como en este artículo señalamos la importancia de analizar y reflexionar sobre o hacia dónde mirar en los procesos de enseñanza y en el desarrollo profesional del profesorado. Entendemos que muchos instrumentos y técnicas de observación y registro de información existentes no son los suficientemente adecuados para comprender la complejidad de la especificidad 
de las situaciones que pretenden describir como, por ejemplo, las vinculadas a las sensaciones y sentimientos de inclusión y exclusión.

Atendiendo a la anterior consideración, planteamos que un procedimiento que contempla la ingenuidad de la mirada del niño del cuento de Andersen es el basado en el registro fotográfico de instantes de la vida en los centros, realizado por los participantes en las situaciones de enseñanza. Será en la confluencia e interrelación de miradas materializadas en fotografías donde se motivarán narraciones que promoverán el conocimiento mutuo de todos los protagonistas en escuelas inclusivas.

\section{Revisión de la literatura}

La protagonista principal, o elemento sustantivo de este artículo, es la escuela inclusiva o aquella que pretende atender formativamente a la diversidad personal, social y cultural del alumnado desde los principios de igualdad, equidad y justicia social en busca de un desarrollo cognitivo, afectivo y social de quienes componen un grupo de iguales (Ainscow, 2017; Cernadas et al., 2019; Leiva, 2019; Moura et al., 2018). En este sentido, uno de los procedimientos metodológicos básicos de la educación inclusiva e intercultural es la creación de espacios y tiempos de relación entre el yo de cada uno y la alteridad de los otros, que les lleve a conocerse y comprenderse. Es así, porque la inclusión no se refiere a alumnos individuales, sino a todo el grupo para que nadie se retrase o quede descolgado (Arnaiz y Escarbajal, 202 1; Booth y Ainscow, 2000).

Con este fin, dichas situaciones deben promover el análisis y reflexión sistemática y crítica sobre prácticas y acontecimientos próximos y relevantes de su entorno familiar, social y escolar que, ineludiblemente, harán aflorar ideas, creencias, afectos y actitudes de los participantes que, a modo de nutrientes, irán construyendo su conocimiento mutuo (Alcalá del Olmo et al., 2020; De Hei et al., 2020; Pujolàs et al., 2013).

Es decir, el profesorado que desarrolle su práctica en ámbitos de educación intercultural e inclusiva debe saber fomentar las relaciones internas y externas de su colegio en las que estén implicados al menos el alumnado, su profesorado y algunos de sus familiares. En la literatura sobre el tema se plantea que es así porque el conocimiento mutuo de los estudiantes en aulas y centros inclusivos se facilitará cuando los docentes posean saberes teóricos y prácticos que les lleven a interpretar sus percepciones, analizarlas y a reflexionar y debatir sobre ellas (Arnáiz et al., 2018; Deppeler y Ainscow, 2016; Echeita y Ainscow, 2011). Estos procesos mentales desencadenados reportarán un conocimiento situado en lugares y tiempos concretos que será relevante y válido para nutrir un programa de contenidos y prácticas curriculares en sintonía con la diversidad del alumnado que ha de interiorizarlo.

Sobre cómo es promovida la práctica docente inclusiva mediante la aplicación de la tecnología digital, en los últimos años se viene hablando de la importancia de la función de adaptabilidad que esta tiene para adecuar el acceso físico, afectivo y cognitivo del alumnado al mundo que lo rodea (Cantillo et al., 2012; García y López, 2012). Ahora bien, consideramos que los actuales productos del desarrollo tecnológico pueden aportar otras funciones en las relaciones entre el alumnado, profesorado y otros agentes en la educación inclusiva, derivadas de características como las de portabilidad, inmediatez y conectividad señaladas por Paidican (2017). Nos referimos a la posibilidad de su usabilidad (Bautista, $2021)$ para promover las citadas interrelaciones mediante situaciones de foto-elicitación y 
narración fotográfica soportadas en híbridos digitales, entre otros, el Smartphone, la Tablet, el ordenador portátil, etcétera (Bautista y Rayón, 2020). A su vez, los actuales híbridos digitales, tienen la virtualidad de soportar diferentes lenguajes o sistemas de representación textual, musical y visual que pueden acompañar al verbal para ampliar o completar relatos personales y grupales del alumnado, profesorado y otros posibles, que aprenden y se conocen mientras lo hacen (Bautista, 2007; Reig, 2012).

Con estos antecedentes, el objetivo del artículo es argumentar sobre la bondad de la práctica sistemática de narraciones fotográficas en el desarrollo profesional docente para formar al profesorado en la participación, en las interacciones internas así como en las relaciones con agentes externos, que son básicas en una educación inclusiva, relevante y de calidad, porque estas son posibles en ambientes vitales y significativos a la vez que afectivamente cálidos como los que se dan en las situaciones de narración individual y grupal que proponemos en el último apartado del artículo.

\section{Desarrollo profesional docente para la inclusión: Enfoques, bondades y limitaciones}

El Emperador estaba desnudo, pero el pueblo hablaba como si estuviera vestido, con un lenguaje ceremonial que hacía olvidar su desnudez y, de esta forma, normalizar y validar la farsa. Se convirtieron en víctimas de su propia manera de hablar y actuar, hasta que un niño pequeño en su sencillez e ingenuidad habló de lo que vio. Vio la desnudez, y la pompa ceremonial saltó por los aires.

Llevando este cuento a la teorización curricular que fundamenta la formación permanente del profesorado para la inclusión, entendemos que es necesario un análisis y deliberación sobre sus diferentes enfoques. Ante los elementos referenciales que bosquejan la educación inclusiva, señalados en la revisión anterior, ¿qué formación teórica y experiencial debe tener el profesorado para poder plantearla y desarrollarla en sus aulas y centros educativos?

Entendemos que las competencias comunicativas dirigidas a la instrucción atribuidas, a la vez que exigidas, al profesorado desde el enfoque curricular técnico, son las de ejecutar un programa de contenidos y acción. Ahora bien, estas no son suficientes en escuelas inclusivas al estar tal plan diseñado por expertos en ámbitos de decisión externos y ajenos a las aulas y centros educativos donde maestras y maestros desarrollan su práctica de enseñanza. Son insuficientes porque, para elaborar acciones situadas de interacción entre el alumnado diverso, es preciso estar inmerso y conocer los entornos físicos y simbólicos donde estas se desarrollen para que sean relevantes. Esto exige a los docentes que viven en ellos saber analizar e interpretar desde una mirada inclusiva los contextos sociales y familiares de enseñanza y, de esta forma, poder reflexionar y debatir sobre qué es lo bueno y noble para sus estudiantes (Bautista, 2013a, 2013b).

De esta forma, es necesaria una noción más flexible de investigación y diseño curricular, y una nueva forma de formación docente que vaya más allá de la racionalidad técnica. Se demanda un enfoque más informado por situaciones reales de enseñanza en aulas y centros que por concepciones ideales imprecisas conceptualmente. Por lo tanto, para que la actuación de maestros y maestras en entornos diversos tenga significado y relevancia social, no solo ha de saber desarrollar un programa de contenidos y acciones, sino que, además, ha de saber elaborarlo, cuestionarlo y transformarlo con el fin de que se mantenga 
situado y, por lo tanto, sea relevante para grupos diversos. Consideramos que ha de ser así porque la educación inclusiva ha de ser transformadora en sintonía con los cambios de las situaciones personales, sociales y afectivas del alumnado; y poder, de esta forma, evitar todas las prácticas excluyentes (Barton, 1996; UNESCO, 1994).

Desde planteamientos curriculares situados y críticos, autores como Freire (1984), Barrow (1984) y Apple (2000), durante décadas vienen cuestionando el empleo frecuente de sistemas de representación en enfoques de formación del profesorado orientados desde la racionalidad técnica, basados en esquemas, diagramas, fórmulas y reglas operativas para presentar ideas sutiles y complejas sobre procesos abstractos como los de inclusión y exclusión educativa. También, critican la rigidez de dicha racionalidad al aplicar modeles y metáforas sobre la enseñanza que, si bien resultaron iluminadores en otro tiempo y lugar, ahora están oxidados en libros de texto y programas de formación. Por lo tanto, son procedimientos que carecen de relevancia formativa por no ser modelos a imitar en situaciones particulares ni, mucho menos, generales de enseñanza.

Es así como desde los planteamientos situados y críticos del curriculum se piensa que todo docente competente debe preservar su flexibilidad, independencia y libertad a actuar ante lo impredecible y emergente, su responsabilidad ante unos fines perseguidos por la comunidad educativa, y su comprensibilidad y variedad para afrontar situaciones únicas e irrepetibles en grupos de enseñanza con alumnado diverso social, cultural y personalmente.

Ahora bien, frente a la rigidez de los modelos de representación y herramientas de observación y registro de información de los procesos formativos en grupos diversos ¿qué se plantea desde los enfoques práctico-situacionales y críticos del curriculum? Entendemos que no es suficiente con acuñar nuevas palabras y frases para describir el proceso de enseñanza o los eventos en el aula porque posiblemente hace que el discurso educativo sea inaccesible y un tanto pretencioso, a menos que represente nuevas ideas o categorías de pensamiento genuinas. De hecho, es poco frecuente que esto suceda, e incluso cuando sucede, es necesario que las nuevas ideas sean fructíferas en términos de la comprensión de los eventos descritos, lo que no siempre es el caso.

Para atender a la diversidad con fines inclusivos el principio de procedimiento que oriente las relaciones en aulas y centros deben fundamentarse en que estas sean mediadas por una multimodalidad representacional de las miradas de los participantes, así como por narraciones personales y grupales sobre dichas miradas en situaciones formativas destinadas a promover el desarrollo profesional docente en entornos diversos social y culturalmente.

Las situaciones formativas que son valiosas para promover sensaciones y experiencias lo suficientemente cercanas e importantes para que el alumnado aborde conjuntamente y sienta la necesidad de percibir y analizar momentos extraordinarios vividos de forma personal y grupal en centros educativos, son las derivadas de propuestas de trabajos que realicen ante una duda, cuestión o extrañamiento de algo inesperado acontecido en el barrio donde está ubicado el colegio o instituto que, como entorno culturalmente diverso que lo envuelve, representa los referentes vitales del alumnado y del conocimiento que construirán en los proyectos de aula y centro. 


\section{Narraciones fotográficas: Esencias para la inclusión educativa}

Como hemos planteado en apartados anteriores, no siempre los nuevos instrumentos de observación son adecuados para acceder y representar las complejidades de la situación que describen. Desde nuestro punto de vista, este es el caso de los entornos de educación inclusiva donde todos deben caminar sin que nadie se quede rezagado o perdido. En este sentido, argumentaremos sobre las bondades que ofrecen las narraciones fotográficas para tal menester.

Hay un valor inherente a los procesos de indagación visual que soporta la construcción de relatos fotográficos, y es que genera unas situaciones formativas relevantes para el alumnado, pero también para el profesorado, al tener oportunidades únicas e irrepetibles de explorar y comprender los contextos sociales y escolares en los que conviven, desarrollar relaciones interpersonales de cercanía, así como reflexionar sobre la vida en las aulas desde marcos interpretativos compartidos.

La construcción de relatos con fotografías tiene como base la indagación narrativa visual, que consiste en que un sujeto genere un relato sobre acontecimientos vividos o sobre alguna idea argumento a partir de la proyección de una imagen o conjunto de imágenes (Bach, 2007). Metodológicamente, una manera de concretar estos procesos de indagación visual es mediante de la foto-elicitación (Bautista, 2019; Clark-Ibáñez, 2007); se pide a los informantes que hagan sus propias fotos para, posteriormente, proyectarlas y, a modo de recuerdos, fomentar la manifestación de las experiencias de vida, significados o emociones de quienes las realizaron.

En nuestro caso, cuando el alumnado tiene la oportunidad de expresar sus experiencias verbal e icónicamente, se ven inmersos en un proceso de activación y construcción del pensamiento creativo. La fotografía es portadora de un lenguaje, el de la imagen, que define en un sistema de representación que soporta tres niveles de información: el denotativo o material, el connotativo o semántico, y el afectivo. El primero hace referencia a la información física o material que representa una fotografía, y los otros dos soportan simbólicamente las ideas o significados, y sentimientos íntimos, respectivamente, del autor de la fotografía. Por ello, cuando la fotografía se hace relato alumbra siempre ideas, significados y referentes a los que sería muy difícil acceder solo con el lenguaje oral, la imagen moviliza pensamientos que difícilmente pueden expresarse con la palabra (Harper, 2002).

Esta particularidad del lenguaje de la imagen define situaciones de indagación narrativa como un aprendizaje experiencial creativo. Las narraciones fotográficas son una oportunidad rica de desarrollo intelectual, dado que en su construcción se hallan implicados procesos de análisis y reflexión a partir de la puesta en juego de elementos racionales y emocionales. Mi familia, Mi barrio, Quién soy yo, Que me gusta y no me gusta del cole, Cómo convivimos en la escuela, Mi aprendizaje .... se constituyen en historias que conmueven y dan que pensar porque las narraciones fotográficas descubren historias no reconocidas o indecibles (Leitch y Michell, 2007).

El procedimiento de foto-elicitación al que antes nos hemos referido, exige al alumnado un trabajo previo de percepción y análisis de la realidad antes de la proyección de las imágenes en el grupo que narra. Un trabajo que encierra una elección, una apertura o escucha atenta a situaciones o instantes que les apelan, inspiran y movilizan, y les lleva a 
captar en una o varias fotografías esos instantes únicos y llenos de significado para ellos. Unas situaciones en el que los alumnos comienzan a conformar una voz consciente, dispuesta a compartir y clarificar las vivencias internas contenidas en las imágenes. Por ello, cuando las imágenes se proyectan en el aula la fotografía hecha relato se apodera de los miembros del grupo quienes, movidos por la curiosidad, extrañamientos o por sus propias interpretaciones, preguntan y cuestionan al autor o autores de las imágenes. Es el momento en el que aparecen matices, incluso nuevos significados, que sumergen al alumnado en procesos de deliberación que alumbran la vida del alumnado, dentro y fuera de la escuela. Como escribe Leitch (2008) "Las fotos por sí mismas no narran. Es el significado que se les da, la voz que hay detrás de la fotografía lo que permite emerger las memorias, el ser provocado, el lugar y el momento es lo que devuelve las fotografías a la vida" (p. 2). Nuevos significados que se verán enriquecidos cuando las imágenes se ordenen en una secuencia final, temporal y/o conceptual para constituir una historia final como una unidad.

Estos procesos de puesta en común y de construcción final de las narrativas, movilizan diálogos emotivos que llenan de contenido la participación del alumnado en el aula y en el centro escolar, diálogos que les permiten comprender sus diferencias, pero también los aspectos que les unen, y en ese diálogo tomar conciencia de las condiciones de su existencia, la propia y la de los otros (Bautista et al., 2012). Si en una escuela inclusiva los alumnos no solo deben de estar presentes, todos tienen que ser reconocidos y encontrar redes sociales de apoyo que les impulsen, las narraciones fotográficas son un procedimiento creativo para construir unas condiciones espacio-temporales para que ello suceda. Los procesos de indagación visual a través de los cuales los niños y niñas construyen sus relatos, son tiempos donde todos los miembros del grupo tienen la oportunidad de conocer con claridad y emoción lo que les ocurre a los compañeros, sus experiencias vitales, anhelos y sueños. Un conocimiento fundamental para empatizar y comprender sus necesidades, el nutriente que enriquece las relaciones interpersonales en un grupo diverso. También, es una oportunidad para que el alumnado gane confianza, pueda expresarse y compartir su voz, lo que contribuye al desarrollo de relaciones de aceptación, cercanía, cuidado y respeto.

Indudablemente, las situaciones formativas generadas en los procesos de indagación narrativa señalados, constituyen para el profesorado una oportunidad de desarrollo profesional. En los trabajos que venimos desarrollando, hemos constatado que los relatos fotográficos devienen en crónicas extraordinarias de lo cotidiano. Una oportunidad para que el profesorado analice y reflexione sobre las situaciones de enseñanza desde los referentes singulares y específicos donde vive el alumnado, a través de sus miradas.

Las narraciones fotográficas atrapan al profesorado, son ventanas que las mentes de los niños y niñas dejan abiertas y aproximan a este a los referentes desde donde interpretan la realidad, piensa, actúan y sienten. Sitúan al profesorado ante diferentes modos y condiciones de vida, diferentes circunstancias personales y sociales, y diversos modos de pensar y sentir. Los docentes participantes en los procesos de indagación narrativa que hemos llevado a cabo, valoran las narrativas fotográficas como contra-relatos para transformar la mirada academicista y normalizadora instalada en la escuela (Rayón y de las Heras, 2011). Estos argumentos son importantes porque la educación inclusiva, como hemos argumentado en la revisión de la literatura, requiere acciones situadas que puedan responder a las necesidades personales, afectivas y sociales de alumnos y alumnas concretos para evitar la exclusión. 
Qué dificultades experimenta el alumnado y qué circunstancias condicionan su vida en contextos deprimidos y desfavorecidos, o cómo la discapacidad se experimenta como barrera no sólo física, sino también social, pueden constituirse a través de las narraciones fotográficas en un conocimiento que ayude al profesorado a identificar situaciones de exclusión. La fotografía hecha relato encierra una expresión profunda de las identidades de los alumnos y las alumnas, una voz que adquiere una centralidad y fuerza más intensa que si se utilizará solo el lenguaje verbal o escrito. Téngase en cuenta que las narraciones fotográficas pueden conformarse con distintos lenguajes de representación (verbal, textual, visual, musical), por lo que definen un discurso intertextual que amplia y profundiza los significados que pueden comunicarse. La multimodalidad de la representación narrativa con la fotografía facilita la construcción de significados vivos y emotivos, muy difíciles de desarrollar solo a través de un discurso monomodal. Por ello, la construcción de narraciones fotográficas genera relatos consistentes desde el punto de vista semiótico, que intensifican la experiencia de los significados que se comunican (Kress y van Leuween, 2006). Por ello, entendemos que son un buen recurso para transformar y enriquecer el modo en el que el profesorado mira al alumnado y se relaciona con él. No se llega a comprender y valorar la diversidad como una experiencia radicalmente humana, si no tenemos oportunidad de vivir una relación con el otro que me comprometa con él y me permita verlo en su totalidad como ser humano (Calderón y Verde, 2018).

Las consideraciones que acabamos de realizar son importantes porque la escuela inclusiva no es solo presencia de todos los niños y niñas. Requiere, ante todo, y en gran medida, la transformación de las relaciones de responsabilidad y compromiso entre los miembros que conforman el centro escolar para que todo el alumnado participe y se forme con éxito según sus posibilidades, y nadie quede excluido.

En este sentido, las situaciones de indagación narrativa visual basada en fotografías, y los relatos de vida en primera persona (yo y nosotros) a los que dan lugar, deviene en una experiencia clave para que el profesorado experimente ese tacto esencial para una educación inclusiva. Lo que Manen (1998) denomina la activación de la otredad, cuando la voz del otro descentra mi mundo. Los relatos fotográficos del alumnado encierran esa oportunidad, aprender a mirar y comprender de otro modo quiénes son los alumnos y alumnas, qué les sucede y cómo se sienten desde los contextos que habitan. Un procedimiento creativo para resituar la mirada del profesorado, e ir desterrando paulatinamente esa mirada normalizadora a la que antes nos referíamos, que le impiden responsabilizarse y comprometerse con la diversidad en entornos social y culturalmente diversos. La fotografía hecha relato es un modo seductor de aproximación al otro, de acercamiento receptivo y sosegado.

La naturaleza de la indagación visual basada en fotografías y la flexibilidad de los procesos de foto-elicitación que la sostienen, permite generar otras situaciones específicas mediante las cuales el alumnado y profesorado trabajan conjuntamente en la identificación, por ejemplo, de barreras para la inclusión y llegar a acuerdos de mejora. Nos referimos al desarrollo de procesos intencionales y sistemáticos de toma de fotografías en las aulas y en otros espacios de centro escolar para desarrollar situaciones de indagación narrativa visual en ciclos de reflexión-acción (Bautista et al., 2020).

Un argumento que justifica esta propuesta es el nivel de atención y observación a situaciones y momentos formativos que tiene que hacer el profesorado para registrarlos en una fotografía (observación durante la acción). Un ejercicio de extrañamiento y de 
reflexión previa mediante el cual lo familiar puede convertirse en extraordinario, y revelar aspectos y significados antes no tenidos en cuenta. Los profesores, posteriormente, en situaciones de indagación narrativa visual, analizan, debaten y reflexionan con el alumnado sobre los significados soportados en las fotografías (reflexión). Las dudas, cuestionamientos y extrañamientos que realice el alumnado cuando se proyectan las imágenes, ayudarán al profesorado a ver con nuevos ojos esos acontecimientos y situaciones contenidas en las fotografías. Un segundo momento de análisis de las situaciones de enseñanza que favorecerá una reflexión atenta sobre la legitimidad o no de las mismas para promover prácticas inclusivas.

En síntesis, la narración fotográfica es una buena oportunidad para que el profesorado valore las situaciones de enseñanza que desarrolla, cuestione hábitos y construya otras acciones como respuestas compartidas que pueden arbitrarse para garantizar el derecho de aprender de todo el alumnado. La función de indagación visual a la que da lugar es cercana a la de otros estudios, como en los de Julianne Moss, para promover la inclusión educativa (Moss, 2003, 2010 y 201 1; Moss et. al., 2007), o el de Carrington y colaboradores (2007), quienes se han centrado en conocer cómo las narraciones audiovisuales favorecen la creación de entornos educativos que eviten la exclusión social del alumnado más desfavorecido.

\section{Conclusiones}

Desde los trabajos que venimos desarrollando en colegios de Educación Infantil y Primaria, hemos ido construyendo un conocimiento sobre las posibilidades que ofrece la fotografía para contar historias. Relatos que despliegan procesos de observación y registro de acontecimientos y situaciones que adentran al alumnado y profesorado en análisis, reflexiones y debates genuinos sobre sus experiencias en contextos cotidianos. Las narraciones fotográficas y los procesos que las sostienen despliegan relatos de quiénes son y qué hacen y sienten, de tal forma que, al compartirse, alumbran nuevas experiencias y acciones de comprensión mutua.

Narrar con fotografías es adentrarse en el análisis, cuestionamiento y problematización de situaciones, tal y como son vividas por otros, para resignificarlas de un modo compartido y, con ello, abrir espacios para pensarlas de otro modo y actuar en consecuencia. Constituye una dimensión del cambio personal y colectivo que, como hemos expuesto, es la esencia de una pedagogía extraordinaria que concibe el centro educativo como un lugar de acogimiento y compromiso con la formación de todo el estudiantado. En este sentido, la escuela inclusiva requiere un cambio importante que, desde nuestro punto de vista, reside precisamente en las formas en las que el profesorado se relaciona con el alumnado y las familias y, consecuentemente, en cómo se enfrenta a las situaciones de enseñanza en contextos diversos social y culturalmente. Stenhouse (1984) creía firmemente que el profesorado podía cambiar el mundo del aula, y que lo haría cuando se lo creyese. Contar y vivir historias diferentes a través de la fotografía, tal y como aquí hemos argumentado, puede ayudarle en ese menester al tener la posibilidad de mirar y analizar desde una variedad de puntos de vista la vida en la escuela. Siendo esa mirada compartida y problematizadora la esencia para encontrar nuevas ideas y referentes que lleven a maestros y maestras al convencimiento de que una escuela de calidad para todas y todos sí es posible. 


\section{Referencias}

Ainscow, M. (2017). Haciendo que las escuelas sean más inclusivas: Lecciones a partir del análisis de la investigación internacional. Revista de Educación Inclusiva, 5(1), 39-49.

Alcalá del Olmo, M. J., Santos, M. J. y Leiva, J. J. (2020). Metodologías activas e innovadoras en la promoción de competencias interculturales e inclusivas en el escenario universitario. European Scientific Journal, 16(40), 6-23. https://doi.org/10.19044/esj.2020.v16n41p6

Apple, M. (2000). Teoría crítica y educación. Miño y Dávila Editores.

Arnáiz, P., De Haro, R. y Azorín, C. M. (2018). Redes de apoyo y colaboración para la mejora de la educación inclusiva. Profesorado. Revista de Currículum y Formación de Profesorado, 22(2), 2949. https://doi.org/10.30827/profesorado.v22i2.7713

Arnáiz, P. y Escarbajal, A. (2021). Aulas Abiertas a la Inclusión. Dykinson.

Bach, H. (2007). Composing a visual narrative inquiry. En D. J. Clandinin (Ed.), Handbook of narrative inquiry. Mapping a methodology (pp. 280-307). SAGE. https://doi.org/10.4135/9781452226552.n11

Barrow, R. (1984). Giving teaching back to teachers. A critical introduction to curriculum theory. Wheatsheaf Books Limited.

Barton, L. (Comp.). (1996). Discapacidad y sociedad. Morata.

Bautista, A. (2007). Alfabetización tecnológica multimodal e intercultural. Revista de Educación, $343,589-600$.

Bautista, A. (2013a). Funciones del vídeo en la formación del profesorado para una educación intercultural. Educatio Siglo XXI, 31(1), 255-268.

Bautista, A. (2013b). Indagación narrativa visual en la práctica docente. Educación y Futuro, 29, 6979.

Bautista, A. (2019). Estructuras del proceso de foto-elicitación y emergencia de contradicciones en el profesorado en formación. En A. Bautista (Coord.), La fotografía en la formación del profesorado (pp. 87-101). Narcea.

Bautista, A. (2021). Functional resignification and technological innovation as a digital teaching competence. Revista Iberoamericana de Tecnologías del Aprendizaje, 16(1), 93-99. https://doi.org/0.1109/RITA.2021.3052679

Bautista, A., Rayon, L. y De las Heras, A. (2012). Valor de los registros audiovisuales en educación intercultural. Comunicar. Revista Científica Iberoamericana de Comunicación y Educación, 39(20), 169-176. https://doi.org/10.3916/C39-2012-03-07

Bautista, A., Rayon, L. y De las Heras, A. (2020). Use of photo-elicitation to evoke and solve dilemmas that prompt changes primary school teachers' visions. Journal of New Approaches in Educational Research, 9(1), 137-152. https://doi.org/10.7821/naer.2020.1.499

Bautista, A. y Rayon, L. (2020). Los bucles de investigación-acción en educación superior desde los smartphones, la foto-elicitación y la narración fotográfica. En F. Trillo (Coord.), Repensando la educación superior. Miradas expertas para promover el debate (pp. 167-180). Narcea.

Booth, T. y Ainscow, M. (2000). Index for inclusion. CSIE.

Calderón, A. y Verde, P. (2018). Reconocer la diversidad. Textos breves e imágenes para transformar miradas. Octaedro.

Cantillo Valero, C., Roura Redondo, M. y Sánchez Palacín, A. (2012). Tendencias actuales en el uso de dispositivos móviles en educación. La Educación Digital Magazine, 147, 1-27. 
Carrington, S., Allen, K. y Osmolowski, D. (2007). Visual narrative: A technique to enhance secondary students' contribution to the development of inclusive socially just school environments-lessons from a box of crayons. Journal of Research in Special Educational Needs, 7(1), 8-15. https://doi.org/10.1111/j.1471-3802.2007.00076.x

Cernadas, F. X., Lorenzo, M. y Santos-Rego, M. A. (2019). Diversidad cultural y escenarios migratorios. Un estudio sobre formación de profesores. Educar, 55(1), 19-37. https://doi.org/10.5565/rev/educar.9619

Clark-Ibáñez, M. (2007). Inter-city children in sharper focus. Sociology of childhood and photo elicitation interviews. En Gr. C. Stanczak (Ed.), Visual research methods (pp. 167-196). Sage.

De Hei, M., Tabacuru, C., Sjoer, E., Walenkamp, J. y Rippe, R. (2020). Developing intercultural competence through collaborative learning in international higher education. Journal of Studies in International Education, 24(2), 190-211. https://doi.org/10.1177/102831531982622610

Deppeler, J. y Ainscow, M. (2016). Using inquiry-based approaches for equitable school improvement. School Effectiveness and School Improvement, 27(1), 1-6. https://doi.org/10.1080/09243453.2015.1026671

Echeita, G. y Ainscow, M. (2011). La educación inclusiva como derecho: marco de referencia y pautas de acción para el desarrollo de una revolución pendiente. Tejuelo, 12, 26-46.

Freire, P. (1984). La importancia de leer y el proceso de liberación. Siglo XXI Editores.

García, M. y López, R. (2012). Explorando, desde una perspectiva inclusiva, el uso de las tic para atender a la diversidad. Profesorado. Revista de Currículum y Formación de Profesorado, 16(1), 277-293.

Goodson, I. y Scherto, R. G. (2011). Narrative pedagogy. Learning and narrative pedagogy. Peter Lang Publishing.

Gosselin, C. y Meixner, E. (2015). Blank canvas and glass ceiling: Using visual metaphors and narratives to examine pre-service teacher development. Multicultural Perspectives, $17(2)$, 7380. https://doi.org/10.1080/15210960.2015.1022445

Harper, D. (2002). Talking about pictures: a case for photo elicitation. Visual Studies, 17(1), 13-26. https://doi.org/10.1080/14725860220137345

Kress, G. y van Leuwen, T. (2006). Reading images: The grammar of visual design. Routledge. https://doi.org/10.4324/9780203619728

Leitch, R. y Mitchell, S. (2007). Caged birds and cloning machines: How student imagery speaks to us about cultures of schooling and student participation. Improving Schools, 1O(1), 53-71. https://doi.org/10.1177/1365480207073722

Leitch, R. (2008). Creatively researching children's narrative through images and drawings. En P. Thompson (Ed.), Doing visual research with children and young people (pp. 37-58). Routledge.

Leiva, J. (2019). La armonía de la inclusión educativa. Una propuesta formativa para el grado de pedagogía. Comares.

Manen, M. (1998). El tacto en la enseñanza. Paidós.

Moss, J. (2003). Picture this: Visual narrative as a source for understanding diversity in our classrooms. University of Melbourne.

Moss, J. (2010). Visual methods: The exposure of exclusion and inclusion. En R. Hampe y P. Stalder (Eds.), Multimodalität in den künstlerischen therapien (pp. 359-370). Frank \& Timme. 
Moss, J. (2011). Understanding visual and intertextual approaches in pedagogical and curriculum research: A pretext. International Journal of Inclusive Education, 15(4), 379-388. https://doi.org/10.1080/13603110902838805

Moss, J., Deppeler, J., Astley, L. y Pattinson, K. (2007). Student researchers in the middle: Using visual images to make sense of inclusive education. Journal of Research in Special Education Needs, 7(1), 46-54. https://doi.org/10.1111/j.1471-3802.2007.00080

Moura, S., Oliveira, C. y Muniz, R. (2018). A formação do professor frente à educação inclusiva de pessoas com deficiência. Revista Educação, Artes e Inclução, 14(4), 34-56.

Paidican, M. (2017). Los alumnos y los dispositivos móviles en el Colegio Abraham Lincoln. Publicaciones Didácticas, 82, 476-483.

Pujolàs, P., Lago, J. y Naranjo, M. (2013). Aprendizaje cooperativo y apoyo a la mejora de las prácticas inclusivas. Revista de Investigación en Educación, 11(3), 207-218.

Rayón, L. y De las Heras, A. (2011). Etnografía, conocimiento y relaciones interculturales. En A. Bautista y H. Velasco (Coords.), Antropología audiovisual: medios e investigación educativa. (pp. 68-97). Trotta.

Reig, D. (2012). Disonancia cognitiva y apropiación de las tic. Revista TELOS. Cuadernos de Comunicación e Innovación, 90, 9-10.

Stenhouse, L. (1984). Investigación y desarrollo del curriculum. Morata.

UNESCO. (1994). The Salamanca statement and framework for action on special needs education. UNESCO.

\section{Breve CV del/a autor/a}

\section{Antonio Bautista}

Catedrático en el Departamento de Estudios Educativos de la Universidad Complutense de Madrid. Director del grupo de investigación consolidado de dicha Universidad, titulado “Desarrollo Tecnológico, Exclusión Sociocultural y Educación” (DETECESE), referencia 941445. Investigador Principal de proyectos financiados en convocatorias públicas del Plan Nacional I+D+i, del Ministerio de Educación, de la Comunidad de Madrid y de su Universidad. Autor de más de doscientas publicaciones de libros y artículos derivadas de dichos estudios. Colaborador en varias revistas, instituciones y agencias nacionales e internacionales de evaluación (ANECA, ANEP, AVAP, OAPEE, entre otras). Sus trabajos han sido reconocidos con 6 sexenios de investigación por la Comisión Nacional Evaluadora de la Actividad Investigadora (CNEAI). Email: bautista@edu.ucm.es

ORCID ID: https://orcid.org/OOOO-OOO2-5194-7419

\section{Laura Rayón}

Profesora en el Departamento de Estudios Educativos de la Universidad Complutense de Madrid, con evaluación positiva en el Programa de Movilidad del Profesorado de Excelencia de la Universidad Complutense de Madrid (UCM-2019), Miembro del grupo de investigación consolidado de dicha universidad, titulado: "Desarrollo Tecnológico, Exclusión Sociocultural y Educación” (DETECESE) referencia 941445. Los principales logros obtenidos son el resultado de proyectos de investigación competitivos en los que he participado como miembro del equipo, y en otros como investigador principal. Ha disfrutado de distintas estancias postdoctorales como Profesora Invitada, entre la ellas la 
realizada en el Departament of Social Science, Loughborough University (Reino Unido), en la Cátedra del Profesor David Buckingham. E-mail: larayon@ucm.es

ORCID ID: https://orcid.org/0000-0003-0339-8221 